\title{
SYNTHESIS AND CHARACTERIZATION CHITOSAN- GLUTARALDEHIDE ALGINATE BLENDS FOR CANDIDATE HEMODIALYSIS MEMBRANE
}

\author{
S. E. Cahyaningrum ${ }^{1} *$, N. Herdyastuti, A. Firdausa ${ }^{1}$ and D. Yanrita ${ }^{1}$ \\ ${ }^{1}$ Department of Chemistry, Faculty of Mathematics and Natural Science, \\ Universitas Negeri Surabaya, Indonesia-60231 \\ *E-mail : saricahyaningrum@unesa.ac.id
}

\begin{abstract}
The composite membrane was produced by mixing the chitosan and sodium alginate solutions followed glutaraldehyde as a crosslinking agent for filtration of $\mathrm{Ca}^{2+}$ ion, phosphate ion, sodium salicylate, urea, and albumin. The membranes were characterized by FTIR to verify the functional group, tensile testing to test their mechanical stability, the surface morphology analysis, and application of membrane for filtration that minerals. The results showed that the mechanical properties of the membrane the higher the concentration of chitosan in the membrane, the higher the value of modulus young. The morphology analysis showed that this membrane has a diameter of the pore in range nanopore, included in the range of ultrafiltration membrane. The membrane of chitosan glutaraldehyde- alginate was applied for the filtration some minerals with a variety of concentrations. This membrane could filtration $\mathrm{Ca}^{2+}$ and phosphate ion, sodium salicylate, urea and albumins were $5.51 \mathrm{mmol} / \mathrm{L} ; 39.27$ $\mathrm{mg} / \mathrm{L} ; 30.87 \mathrm{mg} / \mathrm{L} ; 500.56 \mathrm{mg} / \mathrm{Land} 0 \mathrm{mg} / \mathrm{L}$, respectively.
\end{abstract}

Keywords: hemodialysis, chitosan- glutaraldehyde - alginate membrane

(C) RASĀYAN. All rights reserved

\section{INTRODUCTION}

Hemodialysis represents a method for the right of kidney patient. ${ }^{1}$ In hemodialysis, blood is filtered through the semipermeable membrane for removing the extra salt and harmful waste. Most polymers used in the preparation of hemodialysis are hydrophobic. Many strategic have been developed to control adsorption blood contact membrane such as using a cleaning, asymmetric membrane ${ }^{2}$, modification membrane with some material. ${ }^{3,4}$ In the biomedical field, biocompatibility of membrane has always been a major concern. ${ }^{5,6}$ Chitosan is natural polymers that produce with deacetylation from chitin $^{7-8}$ that potential for the preparation of membranes for various uses: ultrafiltration, immobilization, hemodialysis and drug delivery. ${ }^{9-10}$ Chitosan membranes have been suggested as a membrane which good solute permeability and mechanical strength. ${ }^{1}$ But the functional group chitosan is weak for binding with the compound in blood. Some modified must do to improve physical characteristic and selective of the membrane. Some modified methods are blending and cross-linking with some compounds. ${ }^{11-14}$ Some compound has been combined with chitosan such as poly(acryl acid $)^{15}$, poly vinyl alcohol ${ }^{1}$, polysulphon/ N,O-carboxymethy $1^{16}$, polysulphon with amphiphilic block ${ }^{17}$, thiourea-formaldehyde. ${ }^{18}$ In this research chitosan blend with calcium alginate. Chitosan and glutaraldehyde as a cross-linking agent.

The alginate is an anionic copolymer of guluronic and mannuronic acid and chitosan a polycation polymer. The formation of polycation-polyanion (polyelectrolyte) complex is mainly driven by an electrostatic mechanism where charge neutralization and bridging such as hydrogen bridging. Chitosanalginate was compatible material that applied to the body. ${ }^{19}$ Many factors can affect the properties and application of membrane. ${ }^{20}$ In we previous study, membrane produces chitosan blend calcium alginate not enough strong for hemodialysis membrane, this blend membrane must modify with glutaraldehyde as a cross-linking agent. The cross-linking with glutaraldehyde can reduce swelling and an improved physical characteristic such as mechanical stability. 


\section{Material and Methods}

\section{EXPERIMENTAL}

Chitosan with deacetylation $>85 \%$ was obtained from ChemIndo Indonesia, Sodium alginate, glutaraldehide, urea was purchased from Sigma Chemical Co (USA). Acetic acid, $\mathrm{NaOH}$, sodium salysilate, albumine, potassium phosphate, were purchased from PT Dianum Indonesia; Reagent Nesler and some chemicals with pure analytical grade were produced Merck Company.

\section{Preparation of membrane Chitosan/glutaraldehyde/calcium alginate}

Chitosan flakes $(1 \mathrm{~g})$ were dissolved in $25 \mathrm{~mL} 0.1 \mathrm{M}$ aqueous acetic acid solution. About $3 \mathrm{~g}$ sodium alginate was dissolved in aquades $100 \mathrm{~mL}$. Both solutions of condensation let one night. The solution of chitosan and sodium alginate mixed with comparison chitosan and alginate equal to $3: 1(\mathrm{v} / \mathrm{v})$. Hereinafter added $2 \mathrm{~mL} \mathrm{HCl} 1 \%(\mathrm{v} / \mathrm{v})$ and $\mathrm{NaOH} 10 \%(\mathrm{~b} / \mathrm{v})$ and mixing with magnetic stirrer until homogeneous. The solution was printed into a Petri Disc $\left(10 \mathrm{~cm}\right.$ in diameter). The solvent was evaporated in $26^{\circ} \mathrm{C}$ for one night. The formed membranes were washed using deminerals water until neutral. The chitosan alginate membrane was added with glutaraldehyde 0.5 and $0.1 \%$ as a crosslinking agent with hydrochloric acid as catalysis. The membrane was washed with demineralized water and then dried at room temperature.

\section{Functional group analysis}

The Fourier transmission infra red spectra (FTIR) were obtained using a Perkin Elmer Spectrum RXI FTIR Spectroctrometer at laboratory MIPA Terpadu, Surabaya State University, Indonesia with a range of wave length in the range $400-4000 \mathrm{~cm}^{-1}$. The composition sample: $\mathrm{KBr}$ is 1:4. The mixture of sample and $\mathrm{KBr}$ was compressed to produce a transparent pellet.

\section{Morphological analysis}

The surface morphological was analysis with Scanning electron micrographs (SEM) (Zeiss. EVO MA 10, Germany). The nitrogen liquid use to froze nanoparticles, snapped, and then vacuum dried. In this research before observed and photographed the sample coated with carbon and gold.

\section{Mechanical Properties}

The mechanical properties of the membrane were analysis with Universal Testing Machine (UTM) with a head load of $5 \mathrm{kN}$. The length of grip was $5 \mathrm{~cm}$ with rate $12.5 \mathrm{~mm} / \mathrm{min}$. The tensile strength was calculated by the equation:

$$
\text { tensilestr ength }=\frac{\max \text { imumload }}{\text { scross }-\mathrm{sec} \text { torial }}\left(\frac{N}{\mathrm{~mm} 2}\right) .
$$

\section{Swelling index}

The membrane of chitosan - alginate cross cut in size $2 \times 2 \mathrm{~cm}^{2}$, later then deliberated by analytical balance as weight early. The membrane of chitosan - alginate soaked in $50 \mathrm{~mL}$ aquades during $0,1,10$, 20, 30, 40, and 50 minutes. After was soaked, the surface of membrane dried with a paper tissue. The weight of membrane at interval time was measured. The procedure was repeated until the membrane weight is constant. The membrane swelling index was calculated with the equation:

$$
\% \text { Swelling } \quad=\frac{W a-W b}{W b} \times 100
$$

Where $\mathrm{Wa}$ is the weight of swollen membrane and $\mathrm{Wb}$ is the weight of the dry membrane.

\section{Permeability Test for the Membranes}

Two compartment chamber of dialysis was used to determine the permeability of membranes to filtering $\mathrm{Ca}^{2+}$, phosphate ion, sodium salicylate, urea, and albumins. One compartment of the chamber was filled with $\mathrm{Ca}^{2+}$, phosphate ion, sodium salicylate, urea and albumins (A) and other compartment was filled with mineral water (B). Diffusion cell placed at thermostat with temperature $37^{\circ} \mathrm{C}$. At certain a time 
interval amount urea which is diffusion to in canister of B taken by counted $1 \mathrm{ml}$. After taken, at canister which is as same as (canister B), then enhanced aquadest with is same volume $(1 \mathrm{ml})$. Each condensation of urea result of diffusion heated at temperature $60^{\circ} \mathrm{C}$ during 30 minutes, dripped by reagent Nesler and let 20 minutes, last thinned in gourd measure $10 \mathrm{ml}$ with aquadest.The concentration of urea which is diffusion measured by Spectrophotometer Shimadzu UV/VIS at $\lambda=409 \mathrm{~nm}$. The result of measurement of absorbance used to determine the concentration of urea which is diffusion. For the test of diffusion of sodium, salicylate is equal to test diffusion of urea. That is in stipulating of rate, condensation of aliquot thinned with condensation of $\mathrm{H}_{2} \mathrm{SO}_{4} 0,1 \mathrm{~N}$ and measurement of its absorbance is done at $\lambda=237 \mathrm{~nm}$ and its absorbance is used to determining the concentration of sodium salysilate which is diffusion. So also with diffusion test of albumin is equal to urea, its difference in stipulating rate, condensation of aliquot needn't be heated and dripped by Nesler reagent is enough thinned with aquadest and measurement of its absorbance is done at $\lambda=280 \mathrm{~nm}$. For the test of diffusion, phosphate is equal with test diffusion for urea, each condensation phosphate was added ammonium molybdate and $\mathrm{SnCl}_{2}$ reagent until stable and the concentration of phosphate was analyzed at $\lambda=700 \mathrm{~nm}$. The concentration of calcium ion was analyzed by using atomic absorption spectrometry (AAS). The percentage of permeability at time was calculated with the equation (1).

$$
t=\frac{C t}{\operatorname{Co}} X 100
$$

Where $C t$ is the concentration sample in the receptor cell at time analysis, $C o$ is the initial sample concentration in the donor cell and $t$ is the analysis time (minute).

\section{RESULTS AND DISCUSSION \\ Synthesis of chitosan/glutaraldehyde/calcium alginate membrane}

In this study, this membrane was synthesis by blending alginate with chitosan and glutaraldehyde as a crosslinking agent. Sodium alginate composes with two mono polymers, guluronic acid, and mannuronat acid. The exchange of sodium ion from the guluronic acids with ion calcium happens when sodium alginate was added with calcium chloride. The calcium ion was binding with carboxylate ion in the guluronic acid. The positive ion from chitosan and calcium ions are competition with the negative charges carboxylic acid groups of alginate. The carboxylate groups from glutaraldehyde bind with oxygen from chitosan. Glutaraldehyde as crosslink agent that stronger structure of the membrane.

\section{Fourier transmission infra red spectra}

The functional group's differences between chitosan, calcium alginate and membrane were showed byinfra red spectra (Fig.-2). The functional group's peaks of chitosan at were a strong and broad band at $3400 \mathrm{~cm}^{-1}$ was characteristic for $\mathrm{O}-\mathrm{H}$; spectra at $1590-1650 \mathrm{~cm}^{-1}$ for $\mathrm{N}-\mathrm{H}$ and at $1378-1320 \mathrm{~cm}^{-1}$ the C-N bond. The spectra at $1631 \mathrm{~cm}^{-1}$ and $2895 \mathrm{~cm}^{-1}$ as result of interaction between amino functional group chitosan with aldehyde groups of glutaraldehyde (Fig.-2c). The overlapping of a band of -NH in -NH$\mathrm{C}=\mathrm{OCH}_{3}$ from chitosan with that of $-\mathrm{C}=\mathrm{N}$ formed Schiff base complex between $-\mathrm{NH}_{2}$ group of chitosan, $\mathrm{COO}^{-}$alginate and $-\mathrm{CHO}$ group of glutaraldehyde.

\section{Surface morphology of membrane}

Figure-3 and 4 showed that membrane morphology was softer and flatten. The pore size membranes were influenced with concentration glutaraldehyde. The pore size measures able to identify by that membrane included in membrane ultrafiltration.

\section{Mechanical properties}

Data in Table-1 showed that modulus young membrane with glutaldehyde $0.5 \%$ more bigger than a membrane with glutaraldehyde $0.1 \%$. The mentioned because of glutaraldehyde bind among molecule in the membrane so that can increase structure membrane and more arranger. The ionic-crosslinking interacted enhancement mechanical properties of the membrane. When a functional group of polymer 
RASĀYAN J. Chem.

Vol. 10 | No. 3 |959 - 966 | July - September | 2017

chains has electrostatic interaction with function group another polymer, the interaction experience a restriction in the mobility. This restriction can in an increase in the tensile strength, but the elongation at break of the membrane can reduce.
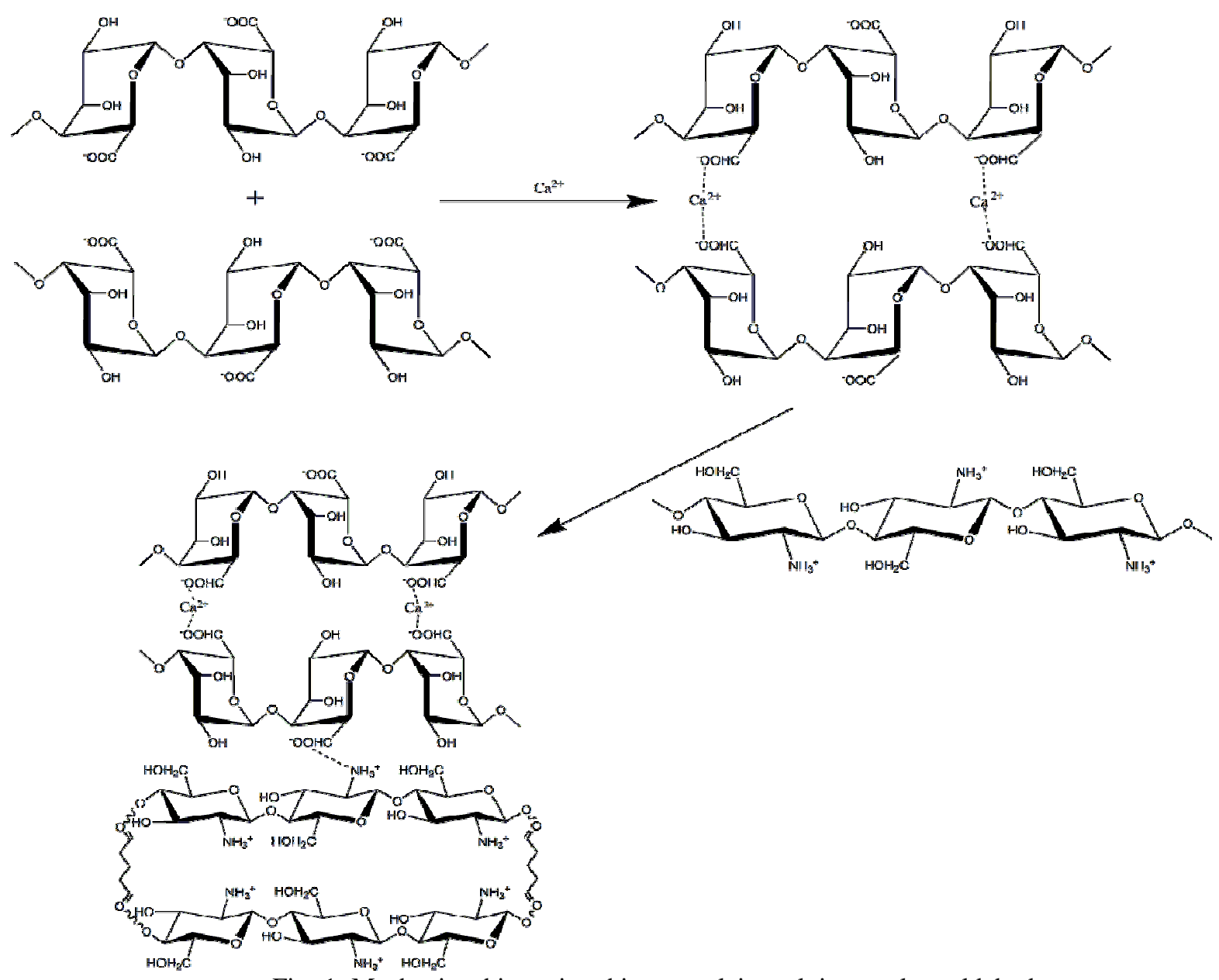

Fig.-1: Mechanism hipotetics chitosan-calcium alginate- glutaraldehyde

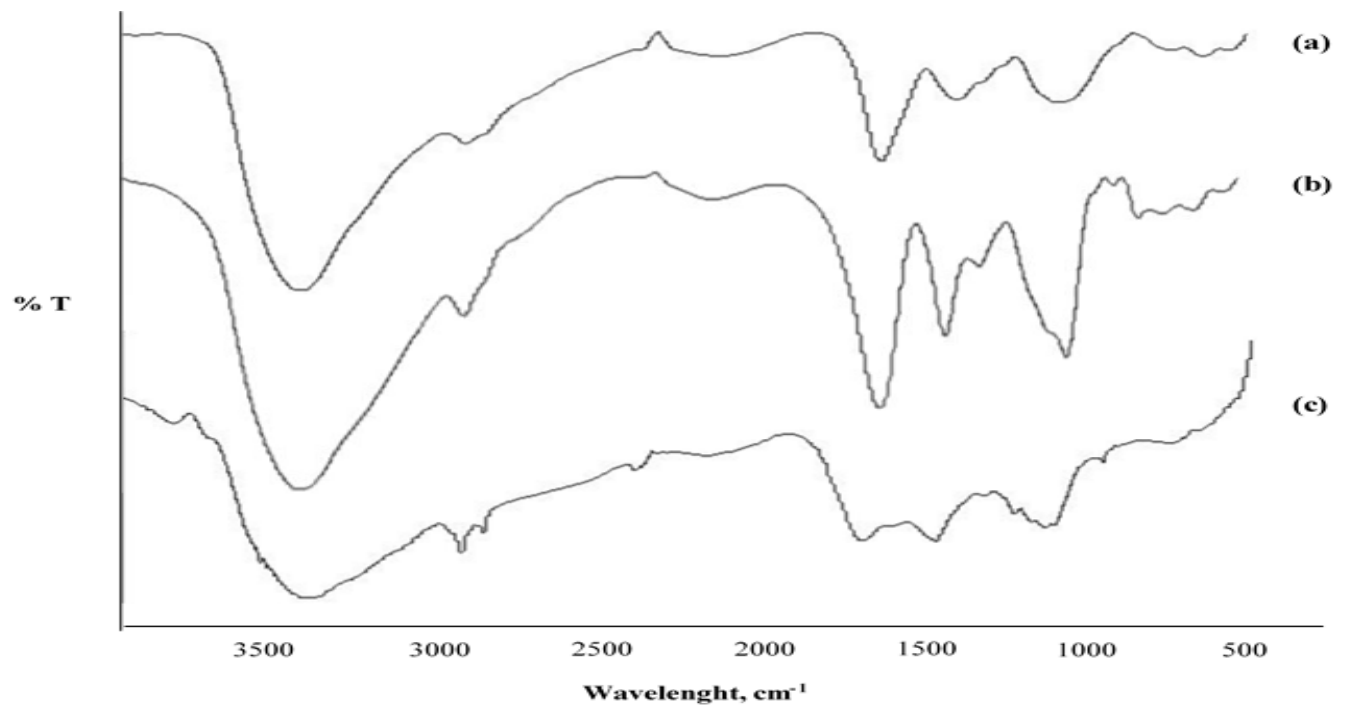

Fig.-2: Spectra IR (a) alginate; (b) chitosan ; (c) membrane 
RASĀYAN J. Chem.

Vol. 10 | No. 3 | 959 - 966 | July - September | 2017

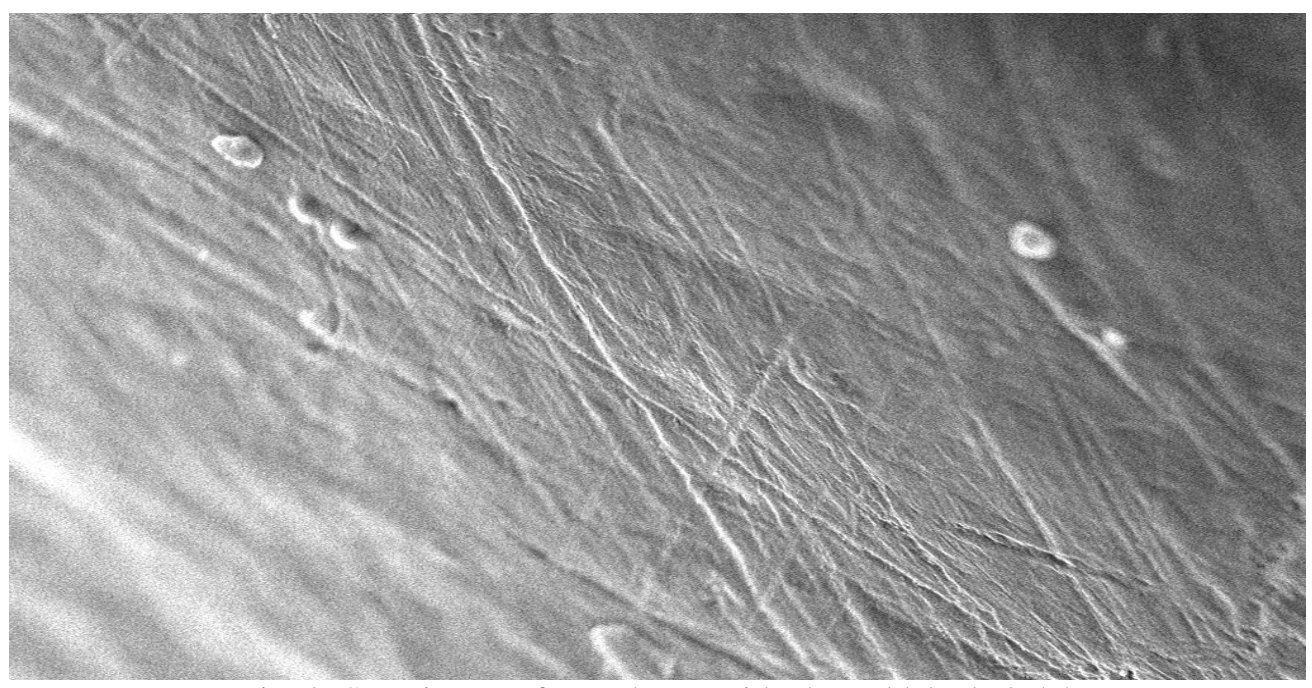

Fig.-3: SEM image of membrane with glutaraldehyde $0.5 \%$

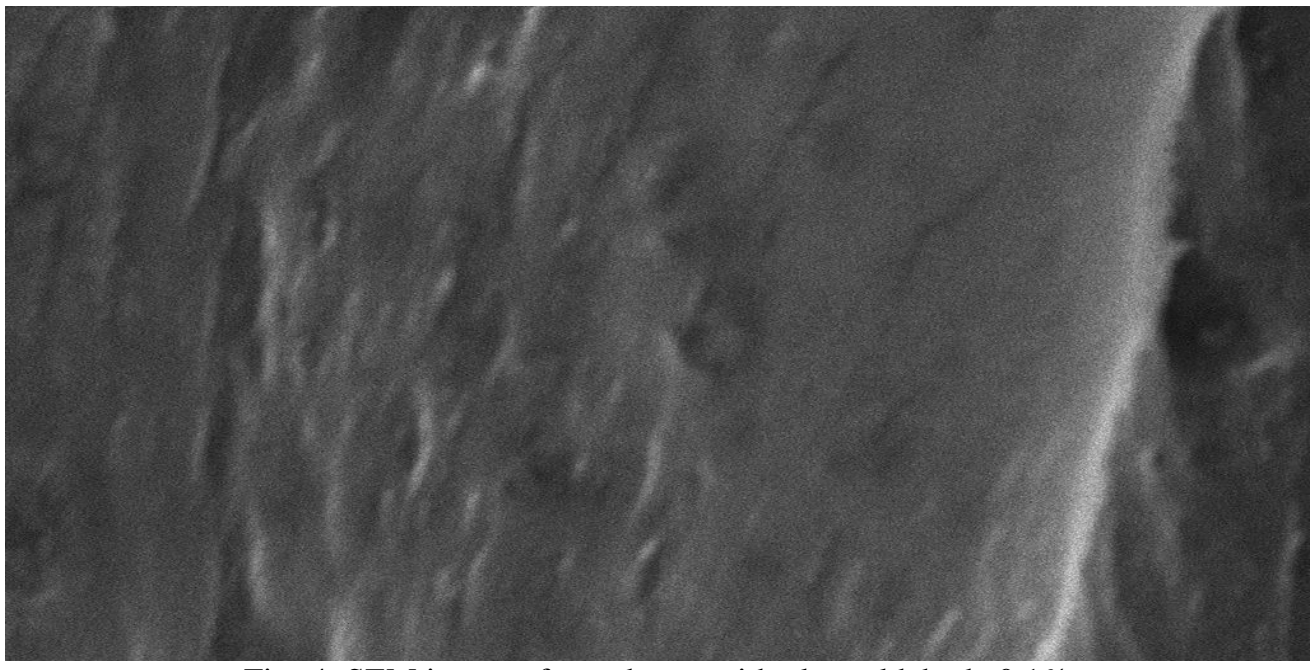

Fig.-4: SEM image of membrane with glutaraldehyde $0.1 \%$

\section{Swelling index}

The hydrophilicity of the membrane is measured by study swelling ratio, study membrane in water absorption capacity. If the membrane is swelling hence penetration solvent into membrane pore progressively easy to, so that membrane resilience to water progressively is downhill. In nature chitosan is hydrophobic and alginate is hydrophilic. So that glutaraldehyde was estimated influence hydrophilicity from membrane because the composition ratio chitosan and alginate on two membranes were same.

Table-1: Tensile strength, percent elongation and Modulus Young

\begin{tabular}{ll|c|c|c}
\hline Membrane & $\begin{array}{c}\text { Tensile strength } \\
\left(\mathrm{N} / \mathrm{mm}^{2}\right)\end{array}$ & $\begin{array}{c}\text { Elongation at } \\
\text { break }(\%)\end{array}$ & $\begin{array}{c}\text { Modulus Young } \\
\left(\mathrm{N} / \mathrm{mm}^{2}\right)\end{array}$ \\
\hline Chitosan-alginate & glutaraldehyde 0.5\% & 44.89 & 4.3 & 10.44 \\
Chitosan- alginate & glutaraldehyde 0.1\% & 40.87 & 4.6 & 8.89 \\
\hline
\end{tabular}

\section{Permeation Studies}

This research used two membranes for filtering $\mathrm{Ca}^{2+}$, phosphate ion, sodium salicylate, urea, and albumin. The results can be shown in Figures- 6 to 9. A normal hemodialysis process for a patient currently takes 5-6 hours with kindly failure, so that in this research the collection data was carried out in intervals 1-12 
h. The $\mathrm{Ca}^{2+}$ has smallest than another compound so that the dialysis rate is fastest passing all the membranes. But albumins can filter in all membranes. The concentration of the solute on the acceptor side of the membrane gradually increased and became constant after 8 hours. Overall percentage reduction solute on membrane chitosan calcium alginate with glutaraldehyde $0.5 \%$ was much higher than in the other membrane.

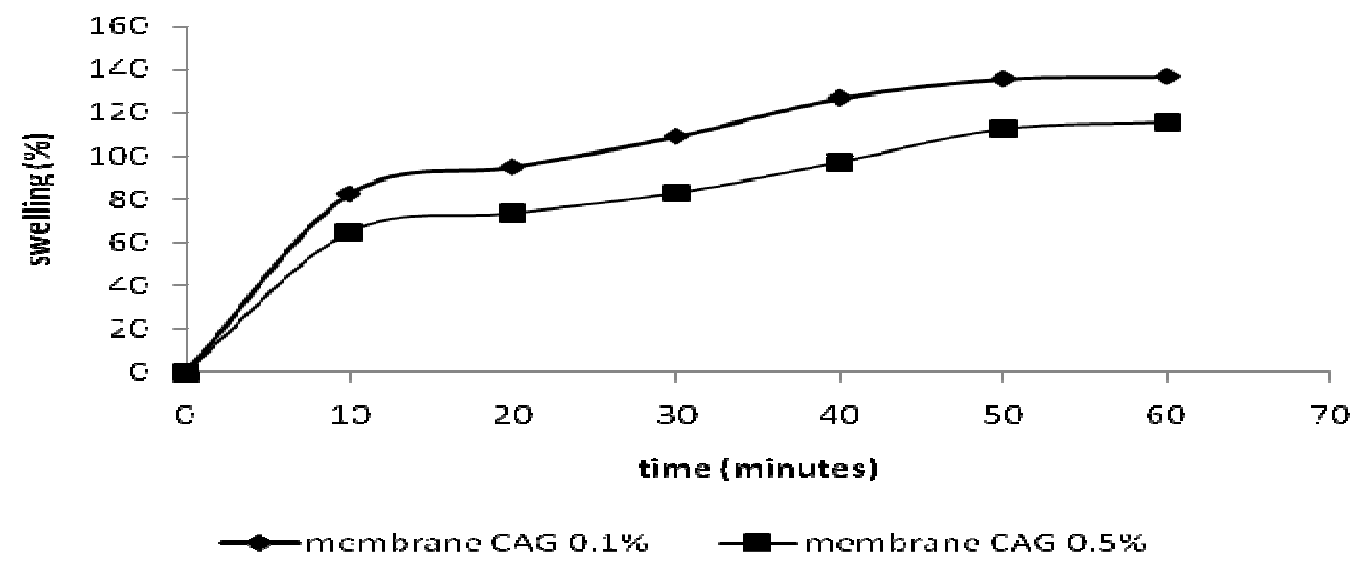

Fig.-5: Swelling (\%) of various membranes

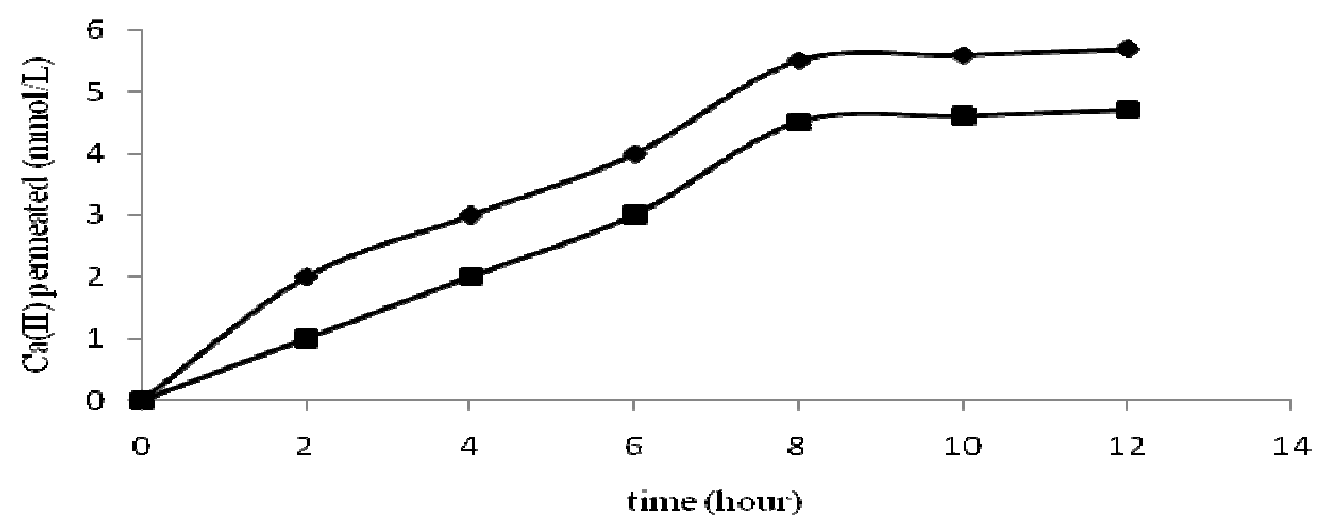

- membrane CAG 0.5\% -membrane CAG $0.1 \%$

Fig.-6: $\mathrm{Ca}$ (II) ion permeated with time in two membranes

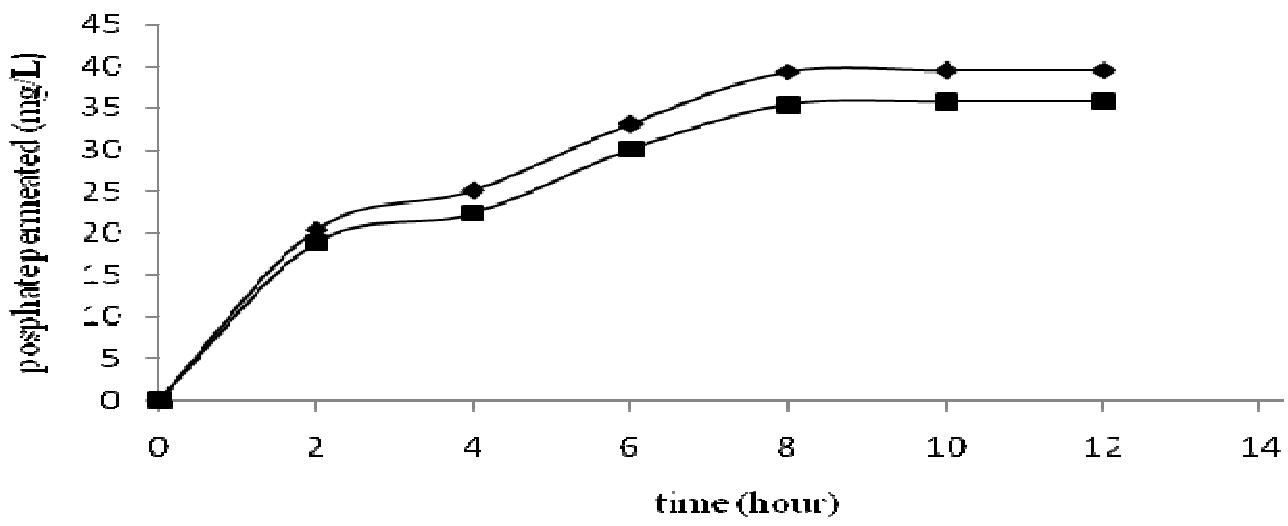

$\rightarrow$ membrane CAG 0.5\% $\rightarrow$-Memorane CAG C.1\%

Fig.-7: Phosphate ion permeated with time in two membranes 
RASĀYAN J. Chem.

Vol. 10 | No. 3 | 959 - 966 | July - September | 2017

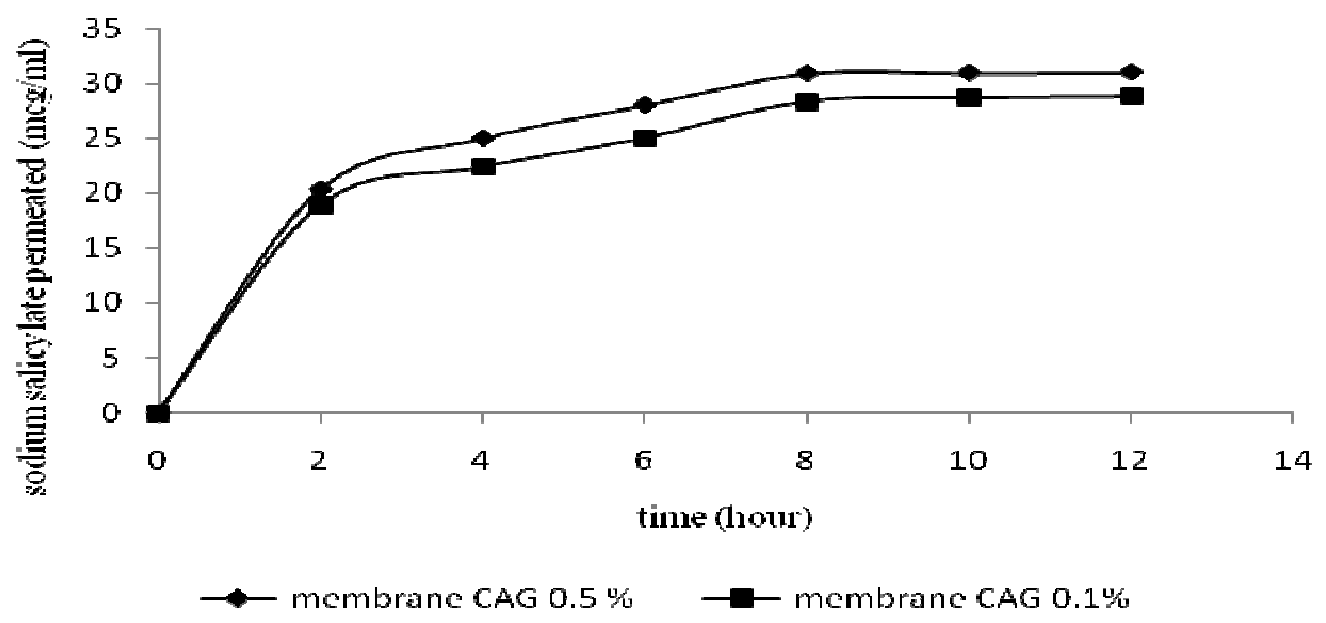

Fig.-8: Sodium salicylate permeated with time in two membranes

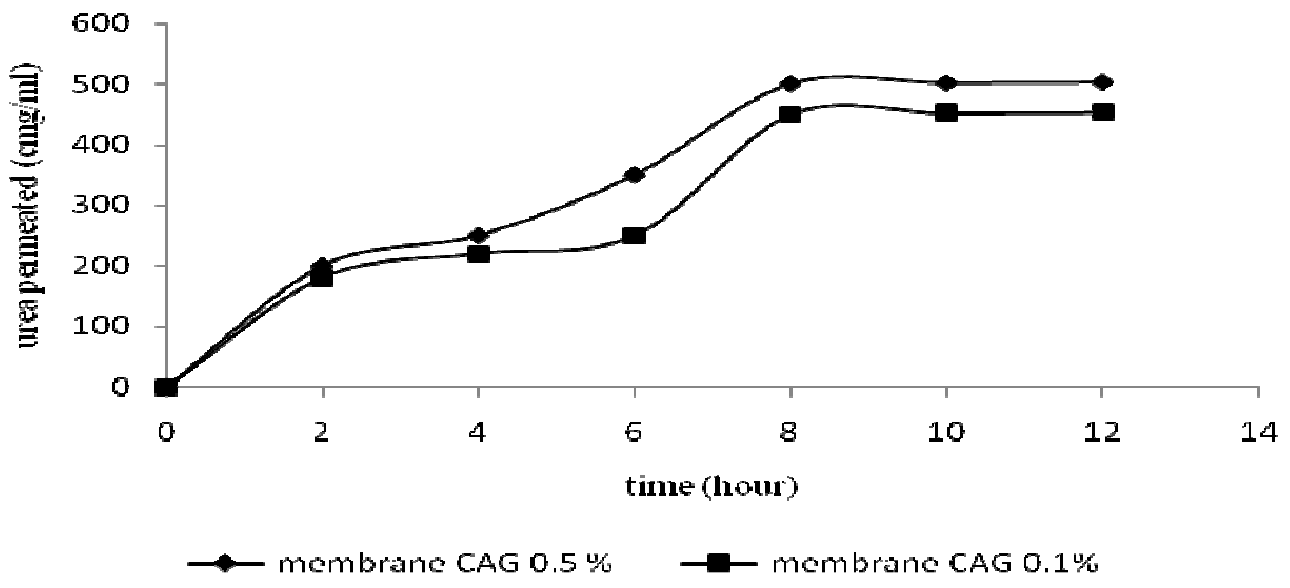

Fig.-9: Urea permeated with time in two membranes

\section{CONCLUSION}

Chitosan calcium alginate membrane network was successfully developed with different concentration glutaraldehyde as crosslink agent. The concentration of glutaraldehyde influenced morphology surface, mechanically, swelling index of the membrane. The influences of polymer content in the casting solution at the mechanical properties membranes were also investigated. With increased glutaraldehyde concentration in the membrane, both the maximum tensile stress and Young's Modulus increased significantly. FTIR studies indicated the presence of functional groups that are characteristic of chitosan, calcium alginate and glutaraldehyde on the surface of the composite membranes. Analysis surface and pore size showed that membrane included in ultrafiltration membrane. The membrane of chitosan glutaraldehyde- alginate was applied for the filtration some minerals with a variety of concentrations. This membrane could filtration $\mathrm{Ca}^{2+}$, phosphate ion, sodium salicylate, urea and albumins were 5.51 $\mathrm{mmol} / \mathrm{L}, 39.27 \mathrm{mg} / \mathrm{L}, 30.87 \mathrm{mg} / \mathrm{L} ; 500.56 \mathrm{mg} / \mathrm{L}$ and $0 \mathrm{mg} / \mathrm{L}$, respectively.

\section{REFERENCES}

1. Lusiana, D. Siswanto, Mudasir and Hayashita, International Journal of Chemical Engineering and Application. 4, 229 (2013).

2. S. A. Altinkaya and B. Ozbas, Journal of Membrane Science. 230, 71 (2004).

3. C. C. Li, T.Y Liu and M. C. Yang, Biomaterials. 25, 1947 (2004). 
RASĀYAN J. Chem.

Vol. 10 | No. 3 |959 - 966 | July - September | 2017

4. X. Ming, F. Tian, J. Yan, C. M.He and F. Li, Chitosan and Alginate Polyelectrolyte Complex membrane and Their Properties for Wound Dress Application. Journal Materials Science:Materials Medical. 21, 1751 (2010)

5. A. Idris, and C. Kee, International Journal of Polymeric Materials, 58, 613. (2009).

6. J.M. Gautham, M. Manavalan, and A. J. Mansoor, International Research Journal of Pharmacy. 4, 16. (2013).

7. V. Halabalova, L. Simek, and P. Mokrejs, Rasayan Journal of Chemistry, 4, 223 (2011)

8. V. Halabalova, L. Simek, and P. Mokrejs, Rasayan Journal of Chemistry, 4, 701 (2011)

9. C. E. Orrego, J. S. Salgado, Valencia, G.I. Gialdo and C.A. Cardona, Carbohydrates Polymer. 79, (2010).

10. S. E. Cahyaningrum, and M. Monica, Bulletin Chemical reaction Engineering and Catalysis, 9 , 263 (2014)

11. T. Uragami, Separation Membranes from Chitin and Chitosan Derivatives. In: Kim S-K (ed), Chitin, Chitosan, Oligosaccharides and Their Derivatives. CRC Press, Boca Raton, Chapter 34, 481 (2011).

12. M. Pieróg, M. Gierszewska-Drużyńska, J. Ostrowska-Czubenko, Effect of ionic crosslinking agents on swelling behavior of chitosan hydrogel membranes. In: Jaworska MM (ed), Progress on Chemistry and Application of Chitin and its Derivatives. Polish Chitin Society, Łódź, 75-82 (2009).

13. V. K. Malesu, D.Sahoo, and P.L Nayak . International. Journal Applied Biology and Pharmaceutical Technology. 2, 402 (2011).

14. D. M. Gierszewska, and C.J. Ostrowska, Influence of crosslinking process conditions on the molecular and supermolecular structure of chitosan hydrogel membrane. In: Jaworska MM (ed), Progress in Chemistry and Application of Chitin and its Derivatives. Polish Chitin Society, Łódź, 15-22 (2011)..

15. W. Ding, C. Liang, S. Sun, L. He and D. Gao. Journal of Material Science.31, 1087 (2015)

16. J. Miao, G. Chen, C. Gao, and S. Dong, Desalination, 233, 147 (2008).

17. Y. Chen, M.Wie, and T.Wong. Journal of Membrane Science.505, 53 (2016).

18. T. J. Sudhavani, N.S. Reddy, K. M. Rao, K. S. V. K. Rao, J. Ramkumar, and A. V. R. Reddy. Bulletin Korean Chemical Society. 34, 1513 (2013).

19. C. Amri, M. Mudasir, D. Siswanto, and R. Roto. International Journal of Biological Macromolecules.82, 48 (2016).

20. I. Gustian, Asdim and E. Maryanti, Rasayan Journal of Chemistry,9, 608 (2016)

[RJC-1635/2017] 